\section{Screening for Drought-tolerant Genotypes of Persian Walnuts (Juglans regia L.) During Seed Germination}

\author{
Kourosh Vahdati ${ }^{1}$ and Naser Lotfi \\ Department of Horticulture, College of Abouraihan, University of Tehran, \\ Tehran, Iran
}

\author{
Bahman Kholdebarin \\ Department of Biology, College of Sciences, Shiraz University, Shiraz, Iran \\ Darab Hassani \\ Department of Horticulture, Seed and Plant Improvement Institute, Karaj, \\ Iran
}

\author{
Reza Amiri \\ Department of Agronomy and Crop Breeding, College of Abouraihan, \\ University of Tehran, Tehran, Iran
}

Mohammad Reza Mozaffari

Agriculture and Natural Resources Research Center, Kerman, Iran

\author{
Charles Leslie \\ Department of Plant Sciences, University of California, Davis, One Shields \\ Avenue, Davis, CA 95616
}

Additional index words. osmotic, polyethylene glycol, rootstock, stress, tolerance, walnut

\begin{abstract}
The effects of osmotic stress induced by polyethylene glycol on the seed germination of 16 walnut genotypes (' $Z_{30}$ ', ' $Z_{53}$ ', ' $Z_{67}$ ', ' $Z_{60}$ ', ' $Z_{63}$ ', ' $K_{72}$ ', ' $\mathbf{B}_{21}$ ', ' $\mathbf{V}_{30}$ ', 'Panegine 20 ', 'Hartley', 'Pedro', 'Vina', 'Lara', 'Serr', 'Ronde de Montignac', and 'Chandler') of Juglans regia $\mathrm{L}$. were studied. Potted seeds were kept under controlled conditions $\left(12 / 12-h\right.$ light/dark photoperiod and $\left.25 \pm 1{ }^{\circ} \mathrm{C}\right)$ during the experiments. The objective was to screen genotypes and determine the critical range of osmotic potential $\left(\psi_{\mathrm{S}}\right)$ for walnut seeds during germination. Decreasing the $\psi_{\mathrm{S}}$ of the germination solutions markedly reduced germination percentage in all genotypes, but there were variations in degree among the genotypes. The $\mathrm{Z}$ genotypes were the most sensitive to osmotic stress, and their germination rates were the lowest at $\psi_{\mathrm{s}}$ more negative than $-0.75 \mathrm{MPa}$. Cluster analysis produced a dendrogram with four groups differing in their tolerance to osmotic stress. Based on factor analysis, four factors explained $\mathbf{9 0 . 4 5 \%}$ of data total variance. Factor analysis showed that tissue fresh and dry weight, tissue water content, and thickness were the most important traits under drought condition. Regression analysis failed to show a significant relationship between percent germination and either seed weight $\left(r^{2}=0.0601\right)$ or kernel weight $\left(r^{2}=0.0258\right)$.
\end{abstract}

Iran is located in the midlatitude belt of arid and semiarid regions of the world (Modarres and Da Silva, 2007). Approximately 42 $\mathrm{M}$ ha of land in these regions in South Asia are affected by salinization (FAO, 1994). Approximately $33 \mathrm{M}$ ha of these areas are in Iran. Walnut trees need large amounts of water for optimum growth and productivity

Received for publication 3 June 2009. Accepted for publication 3 Sept. 2009.

We thank the University of Tehran and the Iran National Science Foundation (INSF) for financial support.

${ }^{1}$ To whom reprint requests should be addressed; e-mailkvahdati@ut.ac.ir. (for example, 'Serr' walnut, 'Texas' almond, 'Lovell' and 'Missouri' peach) have been used for producing rootstocks (Cummins and Aldwinckle, 1983). Because half-sibs are individuals that have one parent in common and differ in the other parent, the mean genotypic value of the group of half-sibs is by definition half the breeding value of the common parent. This reduces the number of seedlings of half-sib families needed as replicates for studying tolerance genes in rootstock breeding programs (Falconer and Mackay, 1996).

Germination is an important stage in the life cycle of species growing under stress conditions, because this stage determines the soil conditions to which plants will be exposed in later stages of their life cycles (Mohammad and Sen, 1990). Soil water supply is an important environmental factor controlling seed germination (Kramer and Kozlowski, 1979).

Osmotic solutions are often used to simulate drought stress in vitro (Pandey and Agarwal, 1998). Polyethylene glycol molecules (PEG 6000) are osmotically active, inert, nonionic, and virtually impermeable to plant cells and are frequently used to induce water stress and maintain uniform water potential throughout the experimental period (Lu and Neumann, 1998).

Although walnut is considered to be sensitive to drought stress, the degree of its tolerance has not been determined at different stages of growth and in different varieties. The objectives of this study were development of a simplified method for determining drought resistance in Persian walnut and evaluation of both commercial varieties and new selections of this species to drought stress.

\section{Material and Methods}

Plant material and chemicals. Half-sib seeds of 16 open-pollinated walnut $(J$. regia L.) genotypes and cultivars (' $Z_{30}$ ', ' $Z_{53}$ ', ' $Z_{67}$ ', ' $\mathrm{Z}_{60}$ ', ' $\mathrm{Z}_{63}$ ', ' $\mathrm{K}_{72}$ ', ' $\mathrm{B}_{21}$ ', ' $\mathrm{V}_{30}$ ', 'Panegine 20 ', 'Hartley', 'Pedro', 'Vina', 'Lara', 'Serr', 'Ronde de Montignac', and 'Chandler') were supplied by the Seed and Plant Improvement Institute (SPII), Karaj, Iran. Seeds of the Z genotypes, $B_{21}$, and the foreign walnut cultivars were collected from the Kamal Shahr Station of Seed and Plant Improvement Institute (SPII) located $1300 \mathrm{~m}$ above sea level at long. $35.51 \mathrm{~N}$, lat. 50.51 E in Karaj. Meteorologically, Karaj is characterized by $240 \mathrm{~mm}$ average annual rainfall, a relatively short $(\approx 2$ months) drought period in the summer, cold winters (minimum temp $-21{ }^{\circ} \mathrm{C}$ ), and 7 months of frost danger (October to April). The seeds of two genotypes, ' $V_{30}$ ' (located $2865 \mathrm{~m}$ above sea level at long. $29.31 \mathrm{~N}$, lat. $56.24 \mathrm{E}$ ) and 'Panegine 20 ' (located $2933 \mathrm{~m}$ above sea level at long. 29.25 N, lat. 56.55 E), were collected from Kerman province in southeastern Iran characterized by $150 \mathrm{~mm}$ average annual precipitation. These two genotypes were very old trees (more than 500 years old), which presumably have experienced 
many drought stress conditions during their lifetimes. Important phenological and agronomic traits of these genotypes are indicated in Table 1.

Seed germination and preparation of osmotic media. Five PEG solutions with osmotic potential $\left(\psi_{\mathrm{S}}\right)$ of $-0.10,-0.50$, $-0.75,-1.00$, and $-1.50 \mathrm{MPa}$ were prepared as described by Michel and Kaufmann (1973). Distilled water was used as a control $(0 \mathrm{MPa})$. Seeds were allowed to germinate at $25 \pm 1{ }^{\circ} \mathrm{C}$ in the light $(12 / 12-\mathrm{h}$ light/dark photoperiod). The number of seeds germinated was recorded every $24 \mathrm{~h}$ for the duration of the experiment ( 29 d) and the final germination percentage for each cultivar and genotype was determined. Polyethylene glycol (PEG 6000) used in this study was obtained from Duchefa Biochemie, Haarlem, The Netherlands.

Before germination tests, seeds were soaked in water for $10 \mathrm{~d}$ and then pretreated with a fungicide (Captan 5\%; Bayer Co., Leverkusen, Germany) before chilling treatment for 4 weeks at 4 to $6{ }^{\circ} \mathrm{C}$ (Vahdati and Hoseini, 2006). At the end of the chilling period, seeds were planted in small polyethylene pots $(250 \mathrm{~mL})$ containing mediumsized perlite granules. Using the Michel and Kaufmann (1973) equation, 50-mL aliquots of PEG solutions with known $\psi_{\mathrm{S}}$ were then added to each pot. The pots were weighed and their surfaces were covered with plastic film to prevent surface evaporation. Pots were then maintained in a growth chamber at $25 \pm 1{ }^{\circ} \mathrm{C}$ and $46 \%$ relative humidity. The pots were weighed every evening and distilled water was added to make up for the amount lost by evaporation. No nutrient solution was added to the pots during the experiment.

When the primary root lengths of the control seedlings $\left(0 \psi_{\mathrm{S}}\right)$ averaged $\approx 4 \mathrm{~cm}$ in length, the following growth indices were recorded for all seedlings: percent seed germination, root dry weights, and shoot fresh weights. For dry weight determination, samples were dried in an oven at $72{ }^{\circ} \mathrm{C}$ for $48 \mathrm{~h}$. Tissue water content was calculated using the (FW-DW)/DW ratio. Also, the final germination percentage (FGP), and mean germination time (MGT) were calculated. The
MGT was estimated as MGT $=\sum$ ni-ti $/ \mathrm{N}$, where $n_{i}$ is the number of seeds that germinated within consecutive intervals of time, $t_{i}$ is the time between the beginning of the test and the end of a particular interval, and $\mathrm{N}$ is the total number of germinated seeds (Hartmann et al., 2001). FGP was calculated from the total number of seeds that germinated during the 29-d period in each growth medium and expressed as a percentage of the initial number of seeds placed in the trays. In addition to the measurements taken at the experiment's conclusion, shoot fresh weights were measured at $4,11,18$, and $25 \mathrm{~d}$ after PEG treatments started and tissue water content was measured $14 \mathrm{~h}, 28 \mathrm{~h}, 54 \mathrm{~h}$, and $108 \mathrm{~h}$ after initiation of PEG treatments.

Statistical analysis. The factorial experimental design for growth indices included two factors $(6 \times 16)$ arranged in a completely randomized design with four replications and 12 seeds per plot (for germination tests, four replications and 50 seeds per plot were used). The experimental factors were six osmotic levels [0.00 (control), $-0.10,-0.50,-0.75$, -1.00 , and $-1.50 \mathrm{MPa}]$ and the 16 genotypes (' $\mathrm{Z}_{30}$ ', ' $\mathrm{Z}_{53}$ ', ' $\mathrm{Z}_{67}$ ', ' $\mathrm{Z}_{60}$ ', ' $\mathrm{Z}_{63}$ ', ' $\mathrm{K}_{72}$ ', ' $\mathrm{B}_{21}$ ', ' $\mathrm{V}_{30}$ ', 'Panegine 20 ', 'Hartley', 'Pedro', 'Vina', 'Lara', 'Serr', 'Ronde de Montignac', and 'Chandler').

Normality of experimental errors was determined using the Univariate and Capability Procedure of SAS Software (SAS Institute Inc., Cary, NC). Data were normalized by using logs of measured indices and square root transformation of shoot fresh weight and root dry weight. After analysis of variance, the means were transformed back to the original scale. Analysis of variance, comparison of means, and regression analyses were performed using SAS (SAS Institute Inc.) software. The mean comparisons were done using Duncan's multiple range test $(P \leq$ $0.05)$. To establish drought-tolerant classes, we grouped the genotypes by cluster analysis using SPSS (SPSS Inc., Chicago, IL). Cluster analysis of genotypes was performed by the unweighted pair group mean average method (UPGMA) using the square Euclidean distance for all traits related to the drought tolerance at the $-1.00 \mathrm{MPa}$ osmotic level. Mean squares of this data were used to determine the number of groups by comparing variations in the square Euclidean distances at each step of cluster analysis (Jobson, 1992).

Factor analysis (Adam and Hwang, 1999) was then used to more clearly identify the most important determinants of drought tolerance. Factor analysis using a principal component method with varimax rotation was performed on correlation matrices for all trait means related to the drought tolerance at $-1.00 \mathrm{MPa} \psi_{\mathrm{S}}$. Factor analysis was performed by SAS (SAS Institute Inc.) and a biplot of the first and the second factors was plotted by Excel (Microsoft Inc., Chicago, IL).

\section{Results}

Germination indices. The germination percentage of genotypes differed significantly in response to osmotic stresses. After application of the control treatment, ' $Z_{60}$ ' $(87.24 \%)$ and 'Pedro' (46.12\%) had the highest and the lowest germination rates, respectively (Fig. 1A).

Germination percentage decreased significantly with decrease in (more negative) water potentials. Also, the effect of osmotic treatment and genotype interactions on the final germination percentage was significant $(P \leq 0.01)$. Maximum seed germination took place in distilled water (87.24\%). Decreasing the water potential to $-1.0 \mathrm{MPa}$ reduced the germination of all varieties to less than $50 \%$ and at $-1.50 \mathrm{MPa}$, the germination decreased to less than $25 \%$ (Fig. 1A). The drought stress treatments were unaffected by the size of seeds or seed weight, and there was not a significant correlation between percent germination and seed or kernel weight.

Growth indices. Because the genotype and osmotic level effects as well as the genotype $\times$ osmotic level interaction were highly significant $(P \leq 0.01)$, the means of the genotypes were compared at each osmotic level by Duncan's multiple range test $(P \leq 0.05)$. A noticeable decrease in root water content was observed after $14 \mathrm{~h}$ of stress treatment (data not shown). The seedlings of ' $\mathrm{B}_{21}$ ' and ' $\mathrm{Z}_{63}$ ' had the highest root

Table 1. Important phenological and agronomic traits of Persian walnut genotypes.

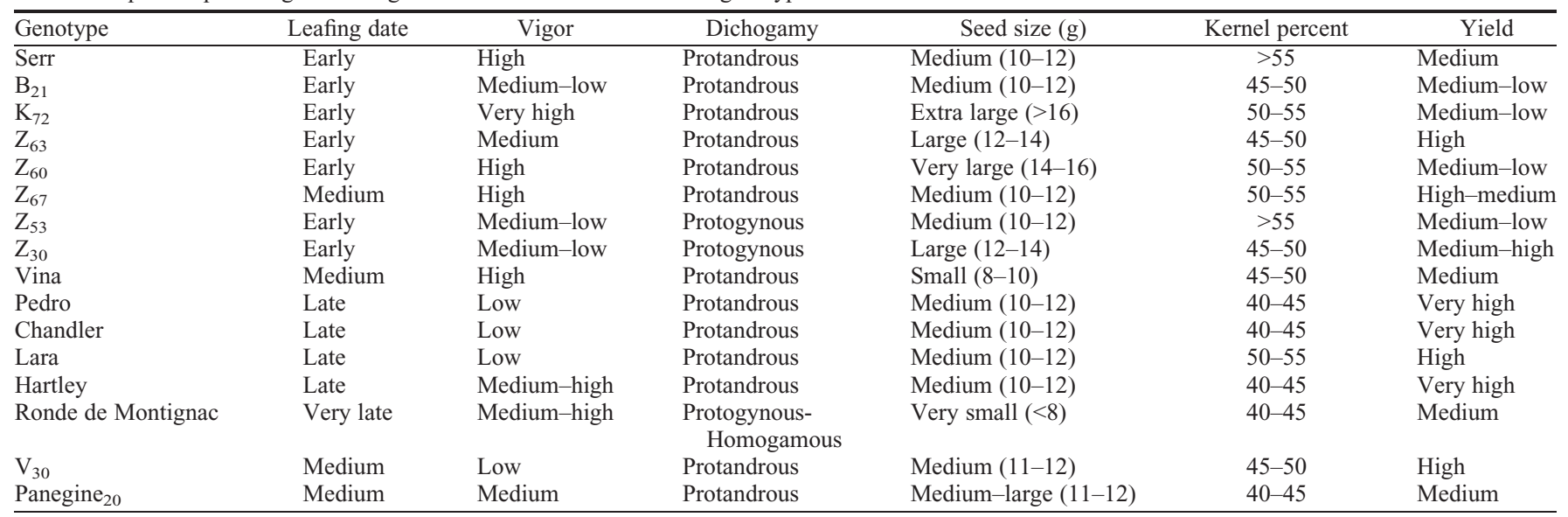




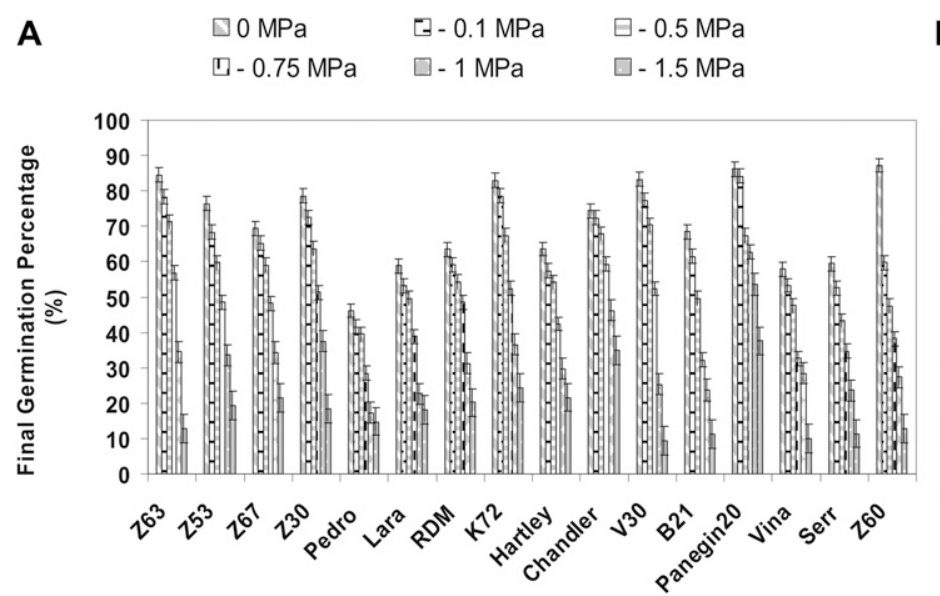

Varieties

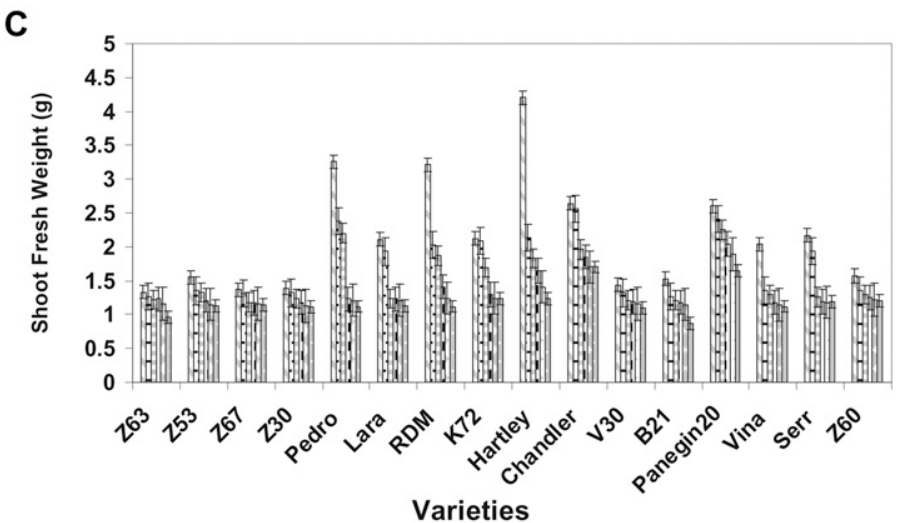

B

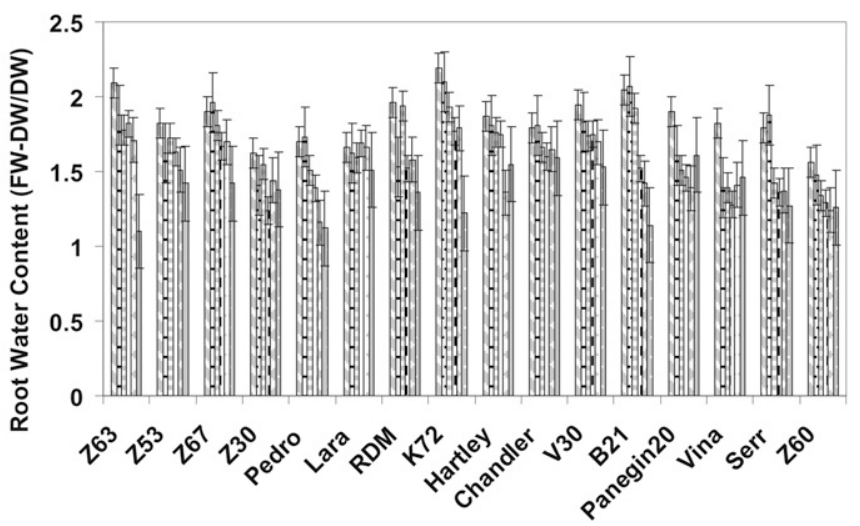

Varieties

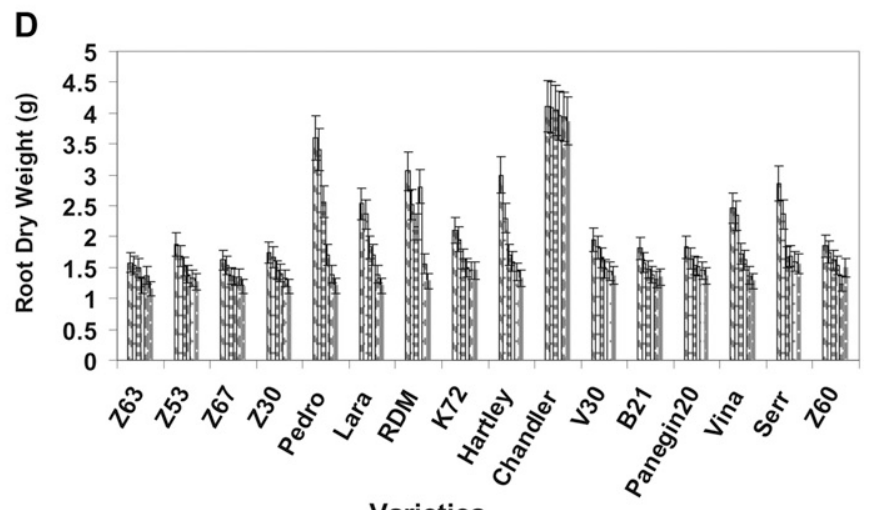

Fig. 1. Effects of osmotic treatment and genotype interaction on the final germination percentage (A), root water content (B), shoot fresh weight $(\mathbf{C})$ and root dry weight of 16 walnut genotypes; each bar represents the mean $( \pm \mathrm{SE})$ of four measurements for three plants per treatment $(P \leq 0.05)$.

water content in the control treatment (distilled water), but the same genotypes had the least root water content at $-1.50 \mathrm{MPa}$ (Fig. 1B). The maximum decrease in shoot fresh weight (FW) was observed after $4 \mathrm{~d}$ of PEG treatment (data not shown). Response of the half-sib families differed as the severity of water stress increased. Under severe osmotic stress $(-1.50 \mathrm{MPa})$, offspring of 'Panegine 20 ' and 'Chandler' had the greatest shoot fresh weight (Fig. 1C).

Root dry weights for the seedlings of many genotypes decreased significantly in response to increased osmotic stress levels. Among tolerant genotypes, differences between root dry weight means were not significant with increasing $\psi_{\mathrm{S}}$ (Fig. 1D).

Among the half-sib families, seedlings of 'Chandler' and 'Panegin ${ }_{20}$ ' had the greatest tolerance, whereas seedlings of ' $\mathrm{B}_{21}$ ' and ' $Z_{63}$ ' had the least tolerance to osmotic drought stress. Seedlings of 'Chandler' and 'Panegine 20 ' withstood stress levels up to $-1.50 \mathrm{MPa}$, whereas ' $\mathrm{Z}_{63}$ ', the least tolerant, showed a threshold of only $-0.75 \mathrm{MPa}$.

Regression analysis. The correlation coefficients for percent germination with seed weight and kernel weight were estimated at $0.0601(P<0.80)$ and $0.0258(P<0.18)$, respectively, and were not significant. As a result, analysis of covariance was not used as a statistical procedure for species-level and family-level analyses.

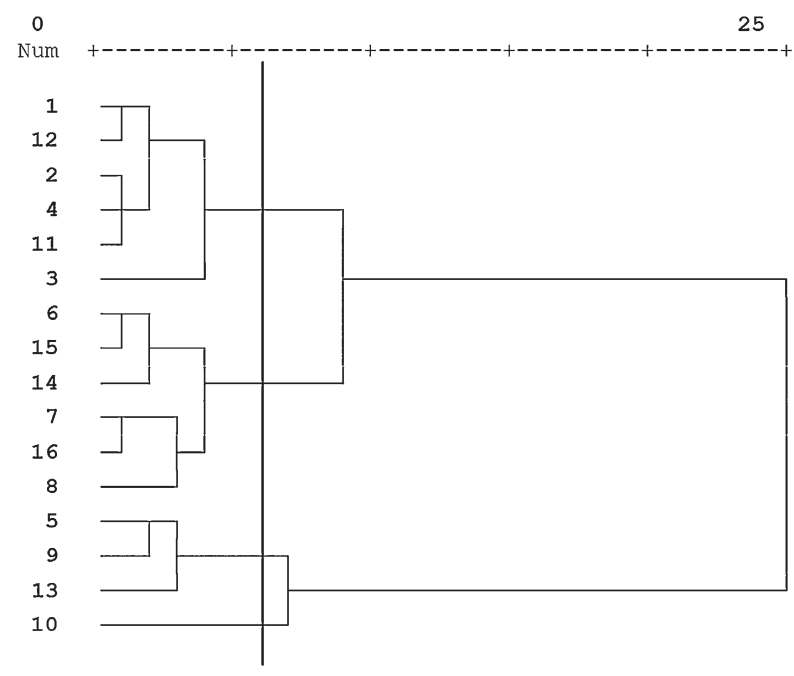

Group 1

B21

$\mathrm{z} 53$

$\mathrm{z} 30$

v30

$\mathrm{Z} 67$

Lara

Serr

Vina

RDM

$\mathrm{z} 60$

K72

Pedro

Hartley

Panegine 20

Chandler

Group 2

Group 3

Group 4

Fig. 2. Dendrogram of the unweighted pair group method with averages clustering algorithm using square Euclidean distance based on all traits related to drought tolerance at the $-1.00 \mathrm{MPa}$ osmotic level. Groups 1 to 4 include sensitive, semisensitive, semitolerant, and tolerant genotypes, respectively.

Cluster analysis. Based on the results of cluster analysis, seedlings of the tested genotypes were classified into four groups; 'Chandler' in the fourth group was the most drought-tolerant genotype, 'Hartley', 'Pedro', and 'Panegin 20 ' in the second group, ' $\mathrm{K}_{72}$ ', ' $Z_{60}$ ', 'Ronde de Montignac', 'Vina', 'Serr', and 'Lara' the third group, and the other genotypes in the first and least tolerant groups (Fig. 2).

Factor analysis. This analysis was performed using all of the characteristics for the 16 studied genotypes (Table 2). Based on factor analysis, four factors explained $90.45 \%$ of data total variance. The first to fourth factors accounted for 32.77, 25.92, 
16.78 , and 14.98 of the variation, respectively. For the first factor, shoot fresh weight (0.93), the shoot dry weight/root dry weight ratio $(0.74)$, and the shoot fresh weight/root fresh weight ratio $(0.66)$ were the traits with the highest positive factor loading. This factor was named the "tissue weight factor." Selection for drought tolerance using this first factor should have the greatest reliability in selecting genotypes expressing drought tolerance at all developmental stages. The second factor had the highest positive factor loading on root $(0.87)$ and shoot $(0.76)$ dry weights and was named the "dry weight factor." The third factor had the highest positive factor loading on the tissue water content ( shoot $=0.98$, root $=0.96$ ) and was named the "water content factor." The fourth factor had the highest positive factor loading on the ratio of shoot to root thickness (0.91) and was named the "thickness factor." To compare the results of factor analysis with grouping the genotypes using cluster analysis, we drew a biplot of the first and the second factor scores for the genotypes (Fig. 3). Classification of the genotypes in the biplot (Fig. 3) showed a high degree of similarity with the cluster analysis results (Fig. 2).

\section{Discussion}

After relieving the osmotic stress by applying distilled water, a high percentage of the seeds that had not germinated under PEG treatments proceeded to germinate. Similar recoveries in seed germination have been reported in the literature (Ungar, 1996). Mehra et al. (2003) indicated that PEG molecules do not enter the seeds and found no phytotoxicity from PEG. Therefore, the decreased germination percentage under PEG treatments can be attributed to reduced water potential. Seeds of all walnut genotypes germinated at $-1.0 \mathrm{MPa} \psi_{\mathrm{S}}$, but their germination was reduced by more than $80 \%$ at $-1.5 \mathrm{MPa}$. The significant delay in seed germination rates observed in response to PEG treatments could be explained by lower rates of imbibition of the water required for seed germination or by variation among genotypes and plant organs in the critical water potential required for cell expansion. This might indicate an important survival mechanism that ensures seed dormancy until sufficient moisture is available for optimal seed germination and seedling establishment.

The ability of tolerant genotypes such as 'Chandler' and 'Panegin 20 ' to germinate at lower $\psi_{\mathrm{S}}$ might be related to their ability to accumulate essential elements in root or shoot tissues under stress condition (Lotfi et al., 2009). Results of our previous study demonstrated genetic differences among walnut genotypes with respect to absorption of calcium, potassium, and magnesium under stress condition (Lotfi et al., 2009).

Osmotic stress also adversely affected the growth of walnut seedlings. Both seedling FWs and dry weights (DWs) decreased with increasing PEG concentrations. The increase

Table 2. Factor analysis for seedling traits of Persian walnut genotypes germinated at $-1 \mathrm{MPa}$.

\begin{tabular}{lcccc}
\hline & \multicolumn{3}{c}{ Rotated factor loading } \\
\cline { 2 - 5 } Trait & First factor & Second factor & Third factor & Fourth factor \\
\hline Root length & 0.63 & 0.52 & 0.03 & -0.39 \\
Shoot length & 0.54 & 0.37 & -0.03 & -0.08 \\
Root fresh weight & 0.03 & 0.72 & -0.35 & -0.14 \\
Shoot fresh weight & 0.93 & 0.25 & -0.12 & 0.07 \\
Root thickness & 0.19 & 0.42 & -0.08 & 0.03 \\
Shoot thickness & 0.26 & 0.37 & -0.01 & 0.23 \\
Root dry weight & 0.38 & 0.87 & -0.31 & -0.04 \\
Shoot dry weight & 0.47 & 0.76 & 0.27 & 0.02 \\
Shoot length/root length & 0.57 & 0.17 & -0.10 & 0.07 \\
Shoot fresh weight/root fresh weight & 0.66 & -0.14 & 0.07 & 0.51 \\
Shoot thickness/root thickness & -0.01 & -0.28 & 0.08 & 0.91 \\
Shoot dry weight/root dry weight & 0.74 & 0.40 & 0.31 & 0.32 \\
Root water content & -0.04 & -0.15 & 0.96 & 0.10 \\
Shoot water content & -0.01 & -0.10 & 0.98 & -0.02 \\
Comparative variance & 32.77 & 25.92 & 16.78 & 14.98 \\
Cumulative variance & 32.77 & 58.69 & 75.47 & 90.45 \\
\hline
\end{tabular}

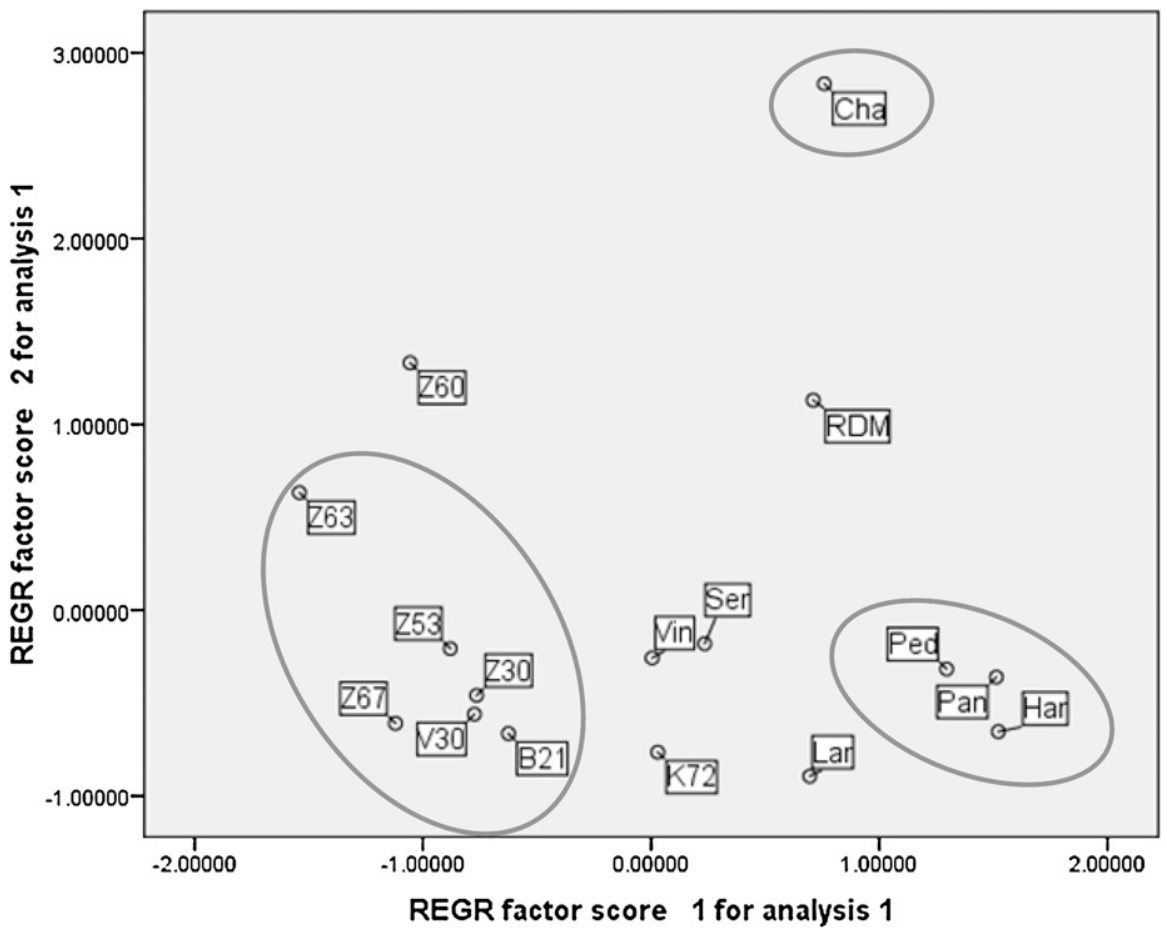

Fig. 3. Classification of walnut genotypes in a biplot of factor analysis according to the first and the second factor scores.

in tissue FW seen in the distilled water treatment was mainly the result of an increase in root water content, as reflected in the (FWDW)/DW values, and can be attributed to increased water absorption (Prado et al., 1995).

In contrast, DW values of roots showed little difference between control and stressed tissues in drought-tolerant genotypes, probably because cell expansion was not accompanied by cell division. Thus, the FW increase can be largely attributed to cell enlargement by water absorption, cell vacuolation, and turgordriven wall expansion (Prado et al., 1995). Our finding of reductions in both germination rates and root dry weight with PEG treatments are in agreement with those reported by Berg and Zeng (2006).

There were clear differences in drought tolerance among the genotypes tested, as reflected in both the germination and growth measurements. The degree of reduction in root dry weight and shoot fresh weight under osmotic stress appears to provide good indicators for tolerance to drought stress in walnut. The effect of osmotic treatment and genotype interaction on the studied growth traits (final germination percentage, root water content, shoot fresh weight, and root dry weight) was significant $(P \leq 0.01)$. Also, the results of the factor analysis and the high amount of factor loading by these traits shows that these traits can be used as phenotypic markers in screening for drought-tolerant walnut genotypes, especially at the germination stage.

Factor analysis revealed which traits are the most important in screening for drought-tolerant genotypes of walnut under stress conditions 
and confirmed the results of the cluster analysis. The combined results indicate that the response to drought stress is consistent within genotypes at different stages of growth from germination to adult. Both analyses showed high similarity in classifying the genotypes and both indicated that seedling genotypes of 'Chandler' and 'Panegine 20 ' were the most drought-tolerant. 'Serr' and 'Lara' were found to be semisensitive genotypes in agreement with the findings of Cohen et al. (1993). In comparing these results with our previously reported study on salt tolerance of walnut, it appears that walnuts are more sensitive to drought stress than to salt stress (Lotfi et al., 2009).

In conclusion, the present study demonstrates variation in the response of walnut genotypes to specific $\psi_{\mathrm{S}}$ and suggests that walnut genotypes could be screened for drought tolerance based on traits examined and the methods used. Results showed that critical $\psi_{\mathrm{S}}$ for walnut seedling growth is -1 $\mathrm{MPa}$ and that seedlings of the tolerant genotypes in this study ('Chandler' and 'Panegine $_{20}$ ') could be used as moderately drought-tolerant rootstocks. This study also showed that water stress differentially affects both seed germination and root and shoot growth in the walnut genotypes studied. As noted in our previous studies, the mechanism of cellular tolerance to both high $\mathrm{Na}^{+}$and high $\psi_{\mathrm{S}}$ may involve sodium excretion, intracellular $\mathrm{Na}^{+}$compartmentalization, and synthesis of osmoprotectants (Lotfi et al., 2009). The tolerant genotypes identified here are candidates for further studies using longer periods of drought, for field studies to determine their suitability for areas with specific environmental conditions, and for use as drought-tolerant rootstocks.

\section{Literature Cited}

Adam, D. and J.T.G. Hwang. 1999. Prediction intervals, factor analysis models and high dimensional empirical linear prediction. Theory and Methods 94:446-455.

Berg, L.V.D. and Y.J. Zeng. 2006. Response of South African indigenous grass species to drought stress induced by polyethylene glycol (PEG) 6000. S. Afr. J. Bot. 72:284-286.

Cohen, M., J. Girona, C. Valancogne, T. Ameglio, P. Cruiziat, and P. Archer. 1993. Water consumption and optimization of the irrigation in orchards. Acta Hort. 335:349-357.

Cummins, J.N. and H.S. Aldwinckle. 1983. Rootstock breeding, p. 294-327. In: J.N. Moore and J. Janick (eds.). Methods in fruit breeding. Purdue Univ. Press, West Lafayette, IN.

Falconer, D.S. and T.F.C. Mackay. 1996. Introduction to quantitative genetics. 4th Ed. Longman Group Ltd., London, UK.

FAO. 1994. Land degradation in South Asia. Its severity, cause and effects upon the people. World Soil Resources Reports, No. 78.

Fulton, A. and R. Buchner. 2006. The effect of water stress on walnut trees growth, productivity and economics, UC Farm Advisors Draft Publication, Tehama County. University of California, Davis, CA.

Hartmann, H.T., D.E. Kester, R.L. Geneve, and F.T Davies. 2001. Plant propagation principles and practices. Prentice Hall, Englewood Cliffs, NJ.

Jobson, J.D. 1992. Applied multivariate data analysis, Vol. II: Categorical and multivariate methods. Springer-Verlag, Berlin, Germany.

Kramer, P.J. and T.T. Kozlowski. 1979. Physiology of woody plants. Academic Press, New York, NY.

Lotfi, N., K. Vahdati, B. Kholdebarin, and E. Najafian Ashrafi. 2009. Germination, mineral composition, and ion uptake in walnut under salinity conditions. HortScience 44:13521357.

Lu, Z. and P.M. Neumann. 1998. Water-stressed maize, barley and rice seedlings show species diversity in mechanisms of leaf growth inhibition. J. Expt. Bot. 49:1945-1952.

Mehra, V., J. Tripathi, and A.A. Powell. 2003. Aerated hydration treatment improves the response of Brassica juncea and Brassica campestris seeds to stress during germination. Seed Sci. Technol. 31:57-70.

Michel, B.E. and M.R. Kaufmann. 1973. The osmotic potential of polyethylene glycol 6000 . Plant Physiol. 51:914-916.

Modarres, R. and V.P.R. Da Silva. 2007. Rainfall trends in arid and semi-arid regions of Iran. J. Arid Environ. 70:344-355.

Mohammad, S. and D.N. Sen. 1990. Germination behavior of some halophytes in Indian desert. Indian J. Exp. Biol. 28:545-549.

Pandey, R. and R.M. Agarwal. 1998. Water stressinduced changes in proline contents and nitrate reductase activity in rice under light and dark conditions. Physiological and Molecular Biology of Plants 4:53-57.

Prado, F.E., J.A. Gonzalez, M. Gallardo, M. Moris, C. Boero, and A. Kortsarz. 1995. Changes in soluble carbohydrates and invertase activity in Chenopodium quinoa (quinoa) developed for saline stress during germination. Cur. Top. Phytol. 14:1-5.

Ungar, I.A. 1996. Effect of salinity on seed germination, growth and ion accumulation of Atriplex patula (Chenopodiaceae). Amer. J. Bot. 83:604-607.

Vahdati, K. 2003. Nursery management and grafting of walnut. Khaniran Pub., Tehran, Iran.

Vahdati, K. and S.H. Hoseini. 2006. Introducing an innovative procedure for large commercial seed lots stratification in Persian walnut. Acta Hort. 705:355-357. 